States is $C$. fenyesi, and its range is confined within that of its seemingly new host, $S$. invicta. Based on the five females described so far, we believe that the host of female $C$. fenyesi will turn out to be an orthopteran. But the female of $C$. fenyesi in the southern United States is likely to have switched hosts, just as the male has done.

A safer course than the suggestion by Orr et al. of the introduction of $S$. invictaspecific phorid flies to the southern United States (which has the risk that these too might switch hosts and damage other species in an alien ecosystem) would be to hunt for the females of $C$. fenyesi and use them for the dispersal of the parasites to control the red imported fire ant. Adult hosts parasitized by Strepsiptera are unable to reproduce and are killed only after the emergence of the strepsipteran ${ }^{4}$; hence while technically a parasite (by host survival), a strepsipteran is effectively a 'parasitoid's. Males and young queens are among the individuals affected. But as it most commonly affects the major workers, which are sterile anyway, $C$. fenyesi is perhaps best considered as a macroparasite of a superorganism, the ant colony, which it debilitates in all the above mentioned ways.

In a curious inversion on the other side of the globe, a hunt is now on for the males of another Myrmecolacidae, Stichotrema dallatorreanum (presumably in an ant), the females of which parasitize and significantly reduce the long-horned grasshopper Sexava sp., a severe pest of oil palm in Papua New Guinea.

J. Kathirithamby

W. D. Hamilton

Department of Zoology,

University of Oxford,

Oxford OX1 3PS, UK
1. Orr, M. R. et at. Nature 373, 292-293 (1995).
2. Kathirithamby, J. \& Johnston, J. S. Ann. ent. Soc. Am. 85, 293-297 (1992).
3. Ogloblin, A. A. Proc. int. Cong. Ent. 2, 1277-1284 (1939).
4. Kathirithamby, J. Syst. Ent. 14, 41-92 (1989).
5. Kathirithamby, J. \& Hamilton, W. D. Trends ecol. Evol. 7 349-351 (1992).

\section{Gonad-specific virus of corn earworm}

SIR - Two closely related species of moths, the corn earworm Helicoverpa zea, in the United States, and the legume pod borer/cotton bollworm $H$. armigera, in Asia, Africa and parts of Europe, constitute major pests of several field crops. In a colony of $H$. zea, maintained at Stoneville, Mississippi, we observed atrophy of the reproductive system in $20-55 \%$ of adults (mean $35 \%$ over seven generations), with no mating observed among such adults.

Here we report the discovery of a previously undescribed virus associated with these agonadal (AG) moths. The AG females have grossly deformed common and lateral oviducts which are almost 100 times the size found in normal females. The common oviduct is full of a white buttery mass of virus-atypical occlusion bodies. The females also have no ovaries, bursa copulatrix, accessory glands or spermatheca. The AG-males have a normal-looking endophallus, aedeagus and ductus ejaculatorius simplex. The testes do not fuse as in normal males and are very small (about the size found in the third-instar larvae) whereas seminal vesicles, vasa deferentia, duplexes and accessory glands are absent. Atypical occlusion bodies are mainly present in the posterior portion of the ductus ejaculatorius simplex. In most AG-adults, the rectum is greatly swollen and filled with fluid containing many bacteria.

Ultrastructural studies have shown that the virus is confined to the reproductive system; therefore we designate it a gonadspecific virus (GSV). In the female, the lumen of oviduct was full of virus-atypical occlusion bodies, with no visible cytopathology of the adjoining cells. The atypical occlusion bodies differ from those of the typical nuclear polyhedrosis virus (NPV) in that they contain high concentrations of virions and have a granular matrix rather than a typical polyhedrin protein matrix. The occlusion bodies also appear to have a host-derived 'membrane' rather than a virus-derived polyhedronmembrane. No polyhedra typical of $H$. zea NPV (ref. 1) were observed in various tissues (tracheal matrix, hypodermis, fat bodies, oviduct and Malpighian tubules) of GSV-infected insects. The virus was found replicating in nuclei of the cells in

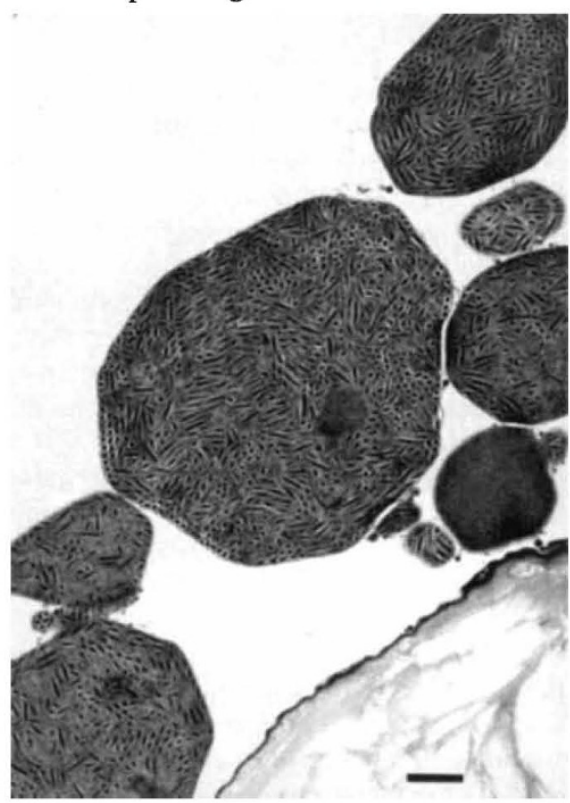

Atypical occlusion bodies of the gonadspecific virus in the lumen of the oviduct of the corn earworm H. zea. Each occlusion body contains many virions. Scale bar, $1 \mu \mathrm{m}$. the distal part of the oviduct. Virions were also seen in the cytoplasm from which clumps of these virions budded into the lumen of the oviduct. The nucleocapsids measured $382 \pm 30 \times 77 \pm 3 \mathrm{~nm}$ $(n=50)$. By contrast, nucleocapsids produced in the typical $H$. zea NPV infection in fat body tissues ${ }^{2}$ measured $318 \pm 18 \times$ $42 \pm 4 \mathrm{~nm}(n=50)$. Preliminary biochemical tests using oligo primers designed to detect various baculovirus genes including the highly conserved polyhedrin gene from the NPV of gypsy moth indicate that GSV is different (E. Dougherty, personal communication). If GSV is a baculovirus, it represents a unique phenotype.

Unlike other known insect baculoviruses, GSV caused no larval mortality, and low (average 26\%) AG condition in adults that were fed as first-instar larvae on a diet smeared with the virus. When newly emerged females were fed on a $10 \%$ sucrose solution containing the crude virus and then allowed to mate on the following day, $25 \%$ females and $40 \%$ males in the resulting progeny were AG. Injection of a crude preparation of GSV at doses as low as 0.001 oviduct equivalents into the abdomen of newly emerged females, and mating of such females to normal males on the following day, resulted in progeny that was $>95 \%$ AG. Because immersing $H$. zea eggs in a crude virus solution did not cause the AG condition in the resulting adults, the virus apparently penetrates the eggs before their chorion is hardened prior to oviposition. The virions of GSV could also be carried by the sperm into the egg at the time of fertilization. These observations suggest a transovarial mode of transmission for GSV.

Normal-looking females among the GSV-infected progeny do carry the virus, perhaps in a low titre, as shown both by electron microscopy of their oviducts as well as by injecting the oviduct homogenates into newly emerged females and examining their progeny. It is therefore feasible that GSV could be introduced into the natural population of $H$. zea by infecting newly emerged females with a very low titre of the virus and releasing these females into the field. Spraying a viral suspension on the plants or providing virus-laced sucrose feeding stations in the fields may be additional methods for dispersing the virus among natural populations. But these possibilities must first be evaluated in field tests.

\section{Ashok K. Raina}

Insect Neurobiology and

Hormone Laboratory,

Jean R. Adams

Insect Biocontrol Laboratory,

USDA Agricultural Research Service,

BARC-East, Beltsville,

Maryland 20705, USA

1. Ignoffo, C. M. Expl Parasit. 33 380-406 (1973).

2. Adams, J. R. \& McClintock, J. T. in Atlas of invertebrate Viruses (eds Adams. J. R. \& Bonami, J. R. ) 87-204 (CRC, Boca Raton, Florida, 1991) 